\title{
Annotations
}

\section{Minimal change nephrotic syndrome and cyclophosphamide}

The term 'minimal change nephrotic syndrome' has become synonymous with the expression 'steroid responsive nephrotic syndrome', the latter term having the merit of focusing on the most important objective characteristic of the condition. Nevertheless, it is somewhat illogical to define this condition by a negative histological feature, which in the majority of cases remains a presumption inferred from the steroid response. It is paradoxical that the major role of immunosuppressive agents in the treatment of the nephrotic syndrome of childhood is in that group with the least convincing evidence of immunopathogenesis-namely, the steroid responders and the patients with minimal change nephrotic syndrome resistant to steroids. Alkylating agents were first used in 1952, and the first report of the use of cyclophosphamide in children occurred more than 20 years ago. ${ }^{1}$

\section{Mode of action}

The nitrogen mustard agents are cytotoxic by virtue of their ability to insert their alkyl chains onto purine bases and so damage deoxribonucleic acid (DNA). Transcription is greatly impeded until the DNA is repaired. The degree of damage to individual cell types will therefore be a function of the rate of cell division and the rate of DNA repair: such variables may underlie the important selective action of cyclophosphamide. By possessing two alkyl side chains cyclophosphamide causes even greater injury by cross linking the twin DNA strands and thus preventing their separation during cell division.

\section{Efficacy}

It is now well established that cyclophosphamide can prevent relapse of the steroid responsive nephrotic syndrome. ${ }^{2-6}$ An eight week course of cyclophosphamide in a dosage of $3 \mathrm{mg} / \mathrm{kg}$ body weight $/ 24$ hours results in about $75 \%$ of cases remaining in remission for one year and $50 \%$ for five years. ${ }^{7}$ Results are better in older children, but children carrying the human leucocyte antigen HLA-B12 do not fare so well. ${ }^{8}$ There is probably no benefit to be gained from longer courses or higher doses, but shorter courses are less effective. ${ }^{-11}$ However, cyclophosphamide is less effective in children in whom relapses occur while on maintenance steroid therapy..$^{12} 13$

The drug is best administered as a single daily dose of $3 \mathrm{mg} / \mathrm{kg}$ oedema free weight during a steroid induced remission. It is of interest that cyclophosphamide is effective even after the induction of a remission with steroids. This suggests that the susceptibility to the disease continues during a steroid maintained remission but is modified by cyclophosphamide, although the patient remains in remission throughout. ${ }^{2}$ This would be consistent with a cyclophosphamide effect at a cellular level.

\section{Toxicity}

Side effects of cyclophosphamide during an eight week course of $3 \mathrm{mg} / \mathrm{kg}$ body weight $/ 24$ hours are rarely severe. A few children will lose appreciable amounts of hair, but it always regrows. Although it is prudent to check the blood counts regularly, severe persistent neutropenia or thrombocytopenia is very unusual. There is an increased risk of infection, and viral diseases, particularly measles and chicken pox, are more severe during treatment with cyclophosphamide. Zoster immune globulin should be given to chickenpox contacts on treatment with the drug. Haemorrhagic cystitis is uncommon with short courses of cyclophosphamide.

The gonadal toxicity of cyclophosphamide seems to be dose related, and a single limited course of 3 $\mathrm{mg} / \mathrm{kg} / 24$ hours for eight weeks (total dose 168 $\mathrm{mg} / \mathrm{kg}$ ) is not necessarily followed by abnormalities of sperm production severe enough to suggest infertility. ${ }^{14}$ Multiple courses of treatment, at the same dosage, may cause oligospermia, especially if concurrent or prescribed within a year of the previous course. Gonadal toxicity in females does not seem to be a problem of clinical importance. Although both male and female patients who have received multiple courses of treatment for the treatment of the syndrome are known to have both 
fathered and conceived children the drug must still be used cautiously, for the long term cost:benefit ratio remains to be evaluated.

Since 1967 nearly 30 cases of pulmonary toxicity, thought to be related to cyclophosphamide treatment for neoplastic disease, have been reported in adults and children and in each case the patient had received other anticancer drugs, either before or simultaneously with cyclophosphamide. To date no report of pulmonary toxicity after conventional cyclophosphamide treatment for minimal change nephrotic syndrome has occurred. The teratogenic effect of cyclophosphamide in man is unclear. Two cases of limb abnormalities have been attributed to cyclophosphamide in pregnant women with neoplastic disease who also received radiotherapy. On the other hand, there are cases in which the drug was given during early pregnancy with no resultant drug related defects.

A higher than chance association of nephrotic syndrome with malignancies has been noted, Hodgkin's disease and lymphomas being particularly associated with the syndrome, although the association is rare in children. The increased risk of malignant disease after treatment with immunosuppressive drugs is well recognised in both adults and children. In a recent review of the occurrence of second tumours in more than 300 patients after anticancer drug treatment three of six children treated with cyclophosphamide developed acute leukaemia, and the total group of cyclophosphamide induced neoplasms are almost exclusively acute leukaemia, carcinomas of the urinary bladder, and squamous cell carcinomas of the skin.

\section{Indications}

Choice of cyclophosphamide as treatment of steroid responders involves an assessment of the relative risks of a relapsing nephrotic syndrome and prolonged corticosteroid treatment on the one hand, as opposed to the ill defined long term hazards of cyclophosphamide on the other. It is not surprising that opinions differ on this difficult issue. As a general rule, it can be agreed that if a child with the syndrome can be maintained in remission on a corticosteroid regimen that does not cause appreciable side effects then treatment with cyclophosphamide is not warranted. Maintenance prednisolone $0.5 \mathrm{mg} / \mathrm{kg}$ body weight on alternate days can almost be tolerated, but at higher doses there is often some growth retardation, indicating the need for cyclophosphamide. The child with minimal change nephrotic syndrome who is resistant to treatment with corticosteroids usually responds to cyclophosphamide $;^{6}$ it is the identification of these patients that is the main purpose of undertaking renal biopsy examination in the steroid non-responders, in whom cyclophosphamide may be life saving. If a child with minimal change nephrotic syndrome resistant to treatment with steroids relapses after cyclophosphamide sensitivity to corticosteroids is usually regained. ${ }^{15}$ In general, patients who relapse after cyclophosphamide should be treated with corticosteroids, and a second course of cyclophosphamide withheld until it is again shown that remission can only be maintained at the expense of unacceptable steroid toxicity.

Surprisingly, the results of a second course of cyclophosphamide in the same dosage are somewhat better in achieving prolonged remission. The case for prescribing a second course can be well supported provided the interval between the two is more than a year.

\section{'Chlorambucil'}

This aromatic derivative of mechlorethamine (nitrogen mustard) has been successfully used since 1966 in steroid dependent, steroid resistant, and frequently relapsing children with minimal change nephrotic syndrome, but it does not seem to be superior to cyclophosphamide. ${ }^{13}$ Although its use has been more limited than cyclophosphamide, doses of chlorambucil rising to $0.3 \mathrm{mg} / \mathrm{kg}$ body weight seem to be as effective in inducing sustained remission. Although short term toxicity seems to be less with this drug than with other alkylating agents, especially when given in a low dose regimen, the long term effects may turn out to be disastrous. The occurrence of acute leukaemia, renal carcinoma, and fatal viral infections suggest that exposure to chlorambucil can only be justified in those with serious steroid toxicity. As with cyclophosphamide, gonadal dysfunction has been reported to be a late complication in prepubertal males: oligospermia and azospermia occur with a cumulative dose of about $6-7 \mathrm{mg} / \mathrm{kg}$ of chlorambucil. ${ }^{16}$

\section{'Nitrogen mustard'}

In 1958 children with pure lipoid nephrosis (minimal change nephrotic syndrome) treated with nitrogen mustard at the end of a course of corticosteroids had a remission of greater duration than those observed after treatment with steroids alone. A recent report suggested a beneficial effect in frequent relapsers who had previously received a multiple course of other immunosuppressive drugs. Schoeneman et al have reported a $46 \%$ sustained remission 27 months after treatment with a single course of nitrogen mustard $(0 \cdot 1 \mathrm{mg} / \mathrm{kg}$ body weight/dose for four days) 
in 12 children, all of whom were steroid responsive. ${ }^{17}$ It may well be that this drug is more effective and less toxic than cyclophosphamide, but, as with other alkylating agents, the role of nitrogen mustard is not established.

Patient benefit and safety must be the main objectives of treatment: the former is obvious, but the latter cannot be assumed. The questions surrounding the use of immunosuppressive or cytotoxic drugs in the treatment of minimal change nephrotic syndrome, a non-malignant condition with an excellent long term prognosis, remains a controversial one.

\section{References}

${ }^{1}$ Coldbeck JH. Experience with alkylating agents in the treatment of children with the nephrotic syndrome. Med $J$ Aust 1963;2:987-9.

2 Barratt TM, Soothill JF. Controlled trial of cyclophosphamide in steroid-sensitive relapsing nephrotic syndrome of childhood. Lancet 1970;ii:479-82.

${ }^{3}$ Tsao YC, Yeung CH. Paired trial of cyclophosphamide and prednisone in children with nephrosis. Arch Dis Child 1971;46:327-31.

4 McCrory WC, Shibuya M, Lu WH, Lewy JE. Therapeutic and toxic effects observed with different dosage programmes of cyclophosphamide of steroid responsive but frequently relapsing nephrotic syndrome. J Pediatr 1973;82:614-8.

5 Chiu JM, McLaine PN, Drummond KN. A controlled prospective study of cyclophosphamide in relapsing corticosteroidresponsive minimal-lesion nephrotic syndrome in children. $J$ Pediatr 1973;82:607-13.

6 Spitzer A, Gordillo PG, Houston IB, Travis LB. Prospective controlled study of cyclophosphamide therapy in children with the nephrotic syndrome. Report of the International Study of Kidney Disease in Children. Lancet 1974;ii:423-7.
${ }^{7}$ Barratt TM, Bercowscy A, Osowsky SG, Soothill JF, Kay R. Cyclophosphamide treatment in steroid-sensitive nephrotic syndrome. Lancet 1975 ; i:55-8.

${ }^{8}$ Trompeter RS, Barratt TM, Kay R, Turner MW, Soothill JF. HLA, atopy and cyclophosphamide in steroid-responsive childhood nephrotic syndrome. Kidney Int 1980;17:113-7.

9 Barratt TM, Carmeron JS, Chantler C, Ogg CS, Soothill JF. A comparative trial of 2 weeks and 8 weeks cyclophosphamide in steroid-sensitive relapsing nephrotic syndrome of childhood. Arch Dis Child 1973;48:286-90.

10 Cameron JS, Chantler C, Ogg CS, White RHR. Long-term stability of remission in nephrotic syndrome after treatment with cyclophosphamide. Br Med J 1974;iv:7-11.

11 McDonald J, Murphy AV, Arneil GC. Long-term assessment of cyclophosphamide therapy for nephrosis in children. Lancet 1974;ii:980-2.

12 Garin EH, Pryor ND, Fennell RS, Richard GA. Pattern of response to prednisone in idiopathic minimal lesion nephrotic syndrome as a criterion in selecting patients for cyclophosphamide therapy. $J$ Pediatr 1978;92:304-8.

${ }^{13}$ Arbeitgemeinschaft für Paediatrische Nephrologie. Effect of cytotoxic drugs in frequently relapsing nephrotic syndrome with and without steroid dependence. N Engl J Med 1977;306:451-4.

14 Trompeter RS, Evans PR, Barratt TM. Gonadal function in boys with steroid-responsive nephrotic syndrome treated with cyclophosphamide for short periods. Lancet 1981;i:1177-9.

15 Bergstrand A, Bollgren I, Samuelsson A, Tornroth T, Wasserman J, Winberg J. Idiopathic nephrotic syndrome of childhood. Cyclophosphamide induced conversion from steroid refractory to highly steroid-sensitive disease. Clin Nephrol 1973;1:302-5.

16 Guesry P, Lenoir G, Broyer M. Gonadal effects of chlorambucil given to pre-pubertal and pubertal boys for nephrotic syndrome. J Pediatr 1978;92:299-303.

${ }^{17}$ Schoeneman MJ, Spitzer A, Greifer I. Nitrogen mustard therapy in children with frequent-relapsing nephrotic syndrome and steroid toxicity. Am J Kidney Dis 1983;5:526-9.

R S TROMPETER Royal Free Hospital School of Medicine, London NW3 